Article

\title{
Estimating chlorophyll-a absorption with the Total Algae Peak Integration Retrieval TAPIR considering chlorophyll-a fluorescence from hyperspectral top of the atmosphere signals in optically complex waters
}

\author{
Therese Keck $^{1, *} \mathbb{D}$, René Preusker ${ }^{1}$ and Jürgen Fischer ${ }^{1}$ \\ 1 Institute for Space Sciences, Freie Universität Berlin, Carl-Heinrich-Becker-Weg 6-10, 12165 Berlin, Germany; \\ e-mail@e-mail.com \\ * Correspondence: therese.keck@wew.fu-berlin.de; Tel.: +49-30-838-56660
}

\begin{abstract}
The Total Algae Peak Integration Retrieval TAPIR relates the chlorophyll-a absorption coefficient at $440 \mathrm{~nm}(a 440)$ to the reflectance peak near $683 \mathrm{~nm}$ induced by chlorophyll-a properties. The two-step retrieval provides both the hyperspectral quantification of the phytoplankton fluorescence and scattering and the estimation of $a 440$ from reflectance signals. Integrating the peak, the Total Algae Peak (TAP) accounts for the variance in the peak's magnitude, shape, and central peak wavelength. TAPIR is a solely optical approach estimating $a 440$ and supports the application of retrieval-independent individual regional bio-optical models afterwards to retrieve the chlorophyll-a concentration. Simulations reveal the major sensitivity on the considered model chlorophyll-a absorption spectrum and its single scattering albedo. Additional water and atmosphere constituents have a low impact. An uncertainty assessment reveals uncertainties of less than $30 \%$ for TAPIR a 440 greater than $0.8 \mathrm{~m}^{-1}$ and less than $38 \%$ for lower $a 440$. In optically complex waters, first validation efforts promise the applicability of TAPIR for high chlorophyll-a concentration estimations in the presence of additional water constituents. The technique is generic and considers external conditions (sun zenith angle, number of measurement bands, surface or satellite measurements, and radiometric quantity). TAPIR applies to all kind of waters including optically complex waters, arctic to tropical regions, and inland, coastal, and open ocean waters. Among other hyperspectral satellite sensors, the Environmental Mapping and Analysis Program (EnMAP) provides sufficient sampling bands for the application of TAPIR.
\end{abstract}

Keywords: fluorescence; absorption; chlorophyll-a; remote sensing; hyperspectral; ocean color; IOP; TAPIR; EnMAP

\section{Introduction}

The space-borne observation of natural waters is mainly limited by three factors: Firstly, strong water absorption restricts passive remote sensing to the visible spectrum (VIS) mostly preventing the application of available measurement bands in the near infrared or beyond.

Secondly, the top of the atmosphere (TOA) measurement is the sum of the water-leaving radiation and the contribution of the atmospheric constituents. Hence, the TOA measurement contains both atmospheric information (e.g. aerosols) and information about the water body. Unfortunately, the atmospheric part of the TOA signal is rather large and water constituent algorithms usually require accurate atmospheric corrections to retrieve the actual water-leaving signal. 
Thirdly, apart from the atmospheric influence, retrieving a particular water constituent can become ambiguous due to various possible optically active constituent (OAC) compositions for a specific TOA signal. The inherent optical properties (IOPs) of the OACs in the water define the resulting water-leaving radiation. In optically complex waters (e.g. at coasts or lakes), Reinart et al. and Zheng et al. $[1,2]$ exemplary reported the superposition of the effects of the IOPs of a wide range of OACs (e.g. phytoplankton, coloured dissolved organic matter (cdom), inorganic particles).

Bio-optical models relate IOPs to biogeochemical variables [e.g. 3-9]. For instance, the phytoplankton chlorophyll-a absorption coefficient at $440 \mathrm{~nm}(a 440)$ can be used to calculate the chlorophyll-a concentration (chl-a) [4] which is a proxy for the amount of phytoplankton.

The blue-green ratios and the polynomial Ocean Colour algorithms (e.g. OC4, OC3, OC4Me) for a wide range of space sensors [10-12] retrieve chl- $a$ in case- 1 waters which contain only phytoplankton [13]. In optically complex waters (case-2), Huot et al. and Gower [14,15] recently demonstrated the complicating impact of mainly cdom on chl-a retrievals due to high $c d o m$ absorption at the required bands for the blue-green ratio.

Jerlov and Doerffer and Fischer $[16,17]$ investigated the spectral absorption from cdom in the visible spectrum from in situ measurements and satellite retrievals, respectively. The absorption of $c d o m$ exponentially decreases from $400 \mathrm{~nm}$ to $800 \mathrm{~nm}$ [18] whereas phytoplankton exhibits the pigment related optical feature of the fluorescence near $683 \mathrm{~nm}$ [19-22]. The amount of chl-a and the photosynthetic activity scale the fluorescence [23]. Therefore, in coastal or inland waters with a contribution of $c d o m$, chl-a retrievals benefit from an accurate estimation of the fluorescence [14,15].

Physically, fluorescence is the process of light emission transforming the energy of a released electron of a relaxed chlorophyll-a molecule which was excited by solar radiation. Although, this phenomenon can occur for both living and deceased phytoplankton cells, this study focuses on animated cells. Besides photosynthesis and heat dissipation, fluorescence is one of the major competitive fates of the absorbed VIS light [24]. Therefore, fluorescence does not only indicate an amount of chl-a but also the "living activity" of phytoplankton although Xing et al. [25] report less than $5 \%$ of the total absorbed light is used for the fluorescence process.

In spite of a rather small fluorescence efficiency, which is the ratio between the number of emitted fluorescent photons and the absorbed photons available for the fluorescence process, of $0.1 \%$ to $1.0 \%$ $[19,20,22,26,27]$, space-borne sensors are able to observe the emitted fluorescence in reflectance spectra [e.g. 28-30].

In the last three decades, the sun-induced fluorescence in waters was investigated theoretically [e.g. 19,20] and in situ [31-33]. Using multispectral measurements from space with, for instance, the Moderate resolution Imaging Spectrometer (MODIS) onboard Aqua and Terra and the Medium Resolution Imaging Spectroradiometer (MERIS) onboard the Environmental Satellite (Envisat), fluorescence can be obtained with fluorescence line height algorithms (FLH) [34-37]. The Ocean and Land Colour Imager (OLCI) onboard Sentinel-3A launched in February 2016 also provides bands for the $F L H$ algorithm.

The FLH estimates the fluorescence magnitude by the difference of measurements at a signal wavelength (e.g. $681.25 \mathrm{~nm}$ for OLCI) and a baseline generated from two additional bands [20]. Unfortunately, the $F L H$ becomes ambiguous for increasing chl-a due to the increased absorption at the local chlorophyll-a absorption maximum near $670 \mathrm{~nm}$. Schalles and Gilerson et al. [21,27], exemplary, report the shift of the peak towards longer wavelength from $680 \mathrm{~nm}$ to $705 \mathrm{~nm}$ for $0 \mathrm{mg} \mathrm{m}^{-3}$ to $30 \mathrm{mg} \mathrm{m}^{-3}$ (redshift). Therefore, FLH algorithms based on a constant single signal wavelength only apply for case-1 waters with low to medium chl-a.

In order to account for the redshift and the changing shape of the effective peak (see fig. 1 and section 2.1) due to chlorophyll-a reabsorption on the peak's blue edge, the increasing water absorption on the peak's red edge [38], and the chlorophyll-a fluorescence, hyperspectral simulations promise improved fluorescence and phytoplankton properties estimations with hyperspectral sensors [27]. 
Besides the Hyperspectral Imager for the Coastal Ocean (HICO) mounted on the International Space Station (ISS) and the Compact High Resolution Imaging Spectrometer (CHRIS) onboard the satellite Project for On-Board Autonomy 1 (PROBA-1), the Earth Observing satellite 1 (EO-1) carried the hyperspectral sensor Hyperion with 220 bands in the VIS and near infra-red (NIR) from November 2000 to January 2017. Recently, the Sentinel-5 Precursor (S5p) carrying the Tropospheric Monitoring Instrument (TROPOMI) was launched in October 2017.

The Hyperspectral Precursor and Application Mission (PRISMA), the Environmental Mapping and Analysis Program (EnMAP), the Hyperspectral Infrared Imager (HyspIRI), and the Plankton, Aerosol, Cloud, ocean Ecosystem (PACE) launching in 2018, 2020, 2022, and 2022, respectively, are promising future space missions for the application of advanced fluorescence and phytoplankton algorithms.

For instance, the Hyperspectral Imager (HSI) onboard EnMAP provides 65 bands with a full width at half-maximum (FWHM) from $6 \mathrm{~nm}$ to $9 \mathrm{~nm}$ within the visible range from $420 \mathrm{~nm}$ to $800 \mathrm{~nm}$ [39]. The comparison of high resolved simulations and the theoretical EnMAP measurements shows a sufficient reproduction of the peak near $683 \mathrm{~nm}$ (fig. 2).

In order to exploit the presumably available hyperspectral TOA measurements and estimate the phytoplankton amount, the Total Algae Peak Integration Retrieval (TAPIR) is introduced. Section 2 demonstrates the peak's variability and quantify phytoplankton with a spectral integration of the Total Algae Peak (TAP) within the fluorescence emission range from $670 \mathrm{~nm}$ to $750 \mathrm{~nm}$. TAPIR is based on the correlation of $a 440$ and the corresponding TAP.

The application of TAPIR for TOA or surface measurements supports a direct estimation of chl-a with an arbitrary bio-optical model adjusted for regional conditions.

Radiative transfer simulations (section 3.1) are used to investigate the sensitivity and uncertainty for various conditions in the water and the atmosphere in section 3.2 and section 3.3. In section 4.2, early validation efforts are performed using in situ measurements described in section 4.1. Furthermore, the findings are discussed in section 5 and the conclusions are presented in section 6 .

\section{Methodology}

\subsection{Rationale}

The phytoplankton and water VIS absorption coefficients, and the fluorescent emission mainly control the magnitude, shape, and location of the effective fluorescence peak.

Section 3.1 introduces radiative transfer simulations which are used for the analysis of the peak and the development of our algorithm. Phytoplankton absorbs light within the total visible spectrum with two local absorption maxima near $440 \mathrm{~nm}$ and $670 \mathrm{~nm}$. Modelling the phytoplankton absorption for the simulations, a normalized absorption spectrum is scaled with the $440 \mathrm{~nm}$ coefficient supporting bio-optical models which usually use chlorophyll-a absorption coefficients near $440 \mathrm{~nm}$ for chl-a retrievals [e.g. 4]. Thus, this study referes to the $440 \mathrm{~nm}$ chlorophyll-a absorption coefficient (a440) for changes in the simulated phytoplankton amount.

For increasing $a 440$, the simulated reflectance increases within the fluorescent interval from $660 \mathrm{~nm}$ to $750 \mathrm{~nm}$ (fig. 1a) due to increased available energy for the emission of fluorescence and the proportionally increased modelled phytoplankton scattering (section 3.1) which additionally increases the reflectance spectrum outside and within the fluorescence spectrum. Additionally, the local reflectance maximum $R\left(\lambda_{P}\right)$ at the maximum peak wavelength $\lambda_{P}$ shifts towards longer wavelengths (fig. 1b). Therefore, using more bands than a constant single signal channel (e.g. $\lambda_{P}=681.25 \mathrm{~nm}$ for the OLCI $F L H)$, the redshift can be considered properly and the estimation of optical phytoplankton properties is enhanced.

The peak is expected to occur within the fluorescent interval from $680 \mathrm{~nm}$ to $710 \mathrm{~nm}$ on top of the generally decreasing reflectance slope (fig. 1a). On the one hand, phytoplankton emits light near $683 \mathrm{~nm}$ due to the fluorescence process [23] and, on the other hand, the total absorption spectrum, 

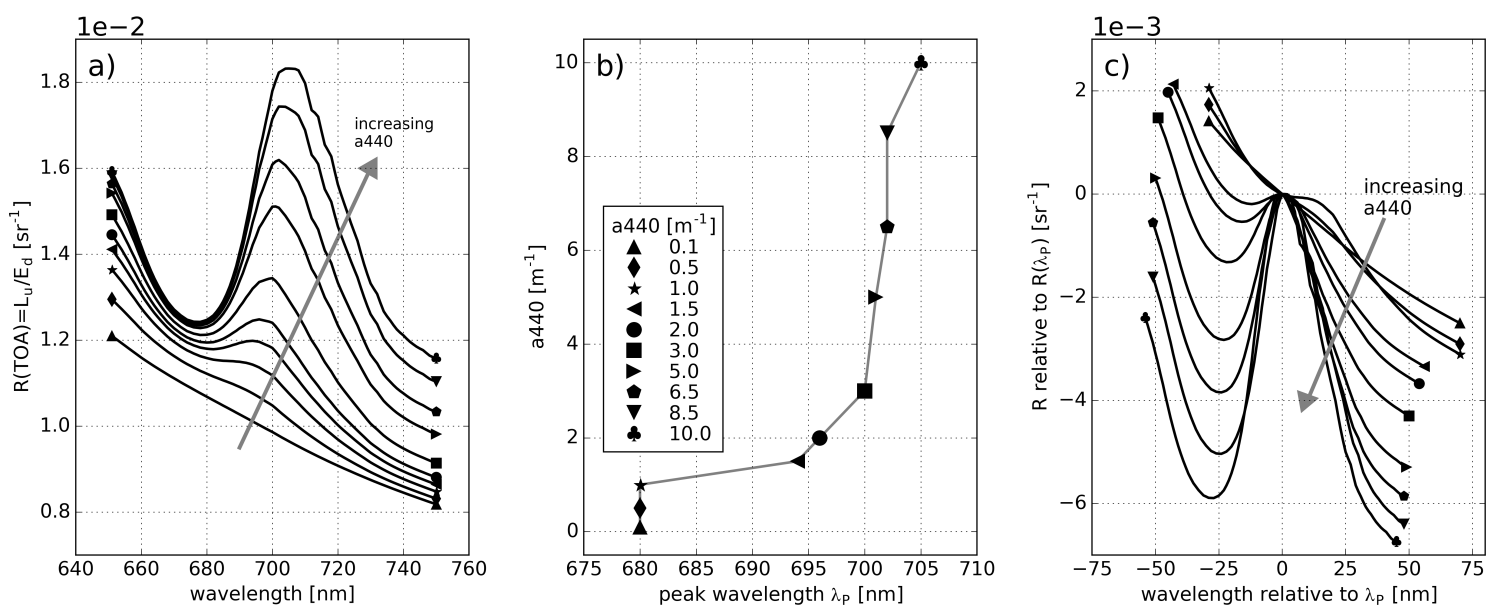

Figure 1. Details of simulated TOA reflectance $R=L_{u} / E_{d}$ for increasing absorption coefficients $a 440$ (indicated by symbols) within $660 \mathrm{~nm}$ to $750 \mathrm{~nm}$. a) Effective fluorescence peak, b) shift of the maximum reflectance $R\left(\lambda_{P}\right)$ towards longer wavelengths (redshift), and c) shape and amplitude of the fluorescence peak relative to the signal wavelength $\lambda_{P}$ and the local maximum $R\left(\lambda_{P}\right)$. The symbols in panels a), b) and c) correspond to the legend in panel b).

which mainly combines water and phytoplankton absorption in the visible, exhibits a local minimum from $675 \mathrm{~nm}$ to $685 \mathrm{~nm}$. In comparison to the sourrounding spectrum, the absorption minimum facilitates the transition of upwelling light which appears as peak in the reflectance spectrum. For increasing $a 440$, the part of the water absorption becomes less important and the effective peak appears to be shifted towards longer wavelengths (fig. 1b). There are constant peak wavelengths of $680 \mathrm{~nm}$ due to a hardly detectable or unapparent peak for low $a 440$ (e.g. $R\left(\lambda ; a 440=0.1 \mathrm{~m}^{-1}\right)$ in fig. 1a) and the maximum at $680 \mathrm{~nm}$ of the decreasing reflectance within this spectral range.

Figure $1 \mathrm{c}$ reveals the relative shape of the effective peak for increasing $a 440$. The peak enlarges with increasing $a 440$ due to increased phytoplankton scattering and fluorescence but its slope narrows due to i) phytoplankton reabsorption near $670 \mathrm{~nm}$ and ii) water absorption.

i). The local chlorophyll-a absorption maximum spectrally expands for higher $a 440$ and reabsorbs emitted fluorescence and scattered radiation. Therefore, the maximum of the peak appears to be shifted towards longer wavelengths and the slope of the peak's left (blue) edge raises.

ii). The peak becomes spectrally broad due to high phytoplankton scattering and fluorescence induced by high $a 440$ and extends to the longer wavelengths beyond $690 \mathrm{~nm}$ where the water absorption rapidly increases. The emitted light from the fluorescence process and the phytoplankton scattering is reabsorbed from water absorption and the peak's right (red) edge becomes steeper.

These two spectral mechanisms are independent and their impact is nonuniform resulting in different peak shapes for increasing $a 440$.

In conclusion, the peak near $683 \mathrm{~nm}$ describes both the phytoplankton fluorescence and the phytoplankton scattering. For an increasing phytoplankton absorption constraining the fluorescence and scattering, the peak exhibits i) an increasing magnitude, ii) a shift towards longer wavelengths, iii) an increasing spectral width, and iv) a squeezed slope. Therefore, in this study, the estimation of the chlorophyll-a properties account for magnitude, shape and spectral position of the peak by a spectral integration. Correlating the Total Algae Peak TAP in section 2.2 from simulated reflectance spectra and the corresponding absorption coefficient $a 440$, the Total Algae Peak Integration Retrieval TAPIR is developed. 


\subsection{Total Algae Peak (TAP)}

In order to obtain the chlorophyll-a properties expressed by TAP, only reflectance residuals shown as shaded areas in fig. 2 are used. Therefore, teh reflectance is reduced by a spectrum dependent constant $R\left(\lambda_{1}\right)$ located at the local reflectance minimum $\lambda_{1}$ within $665 \mathrm{~nm}$ to $678 \mathrm{~nm}$ (eq. (1)) accounting for the local phytoplankton absorption maximum near $670 \mathrm{~nm}$. The lower integration limit $\lambda_{1}$ hardly spectrally shifts for increasing $a 440$.

The upper integration limit is definded with $\lambda_{2}$ where $R\left(\lambda_{1}\right)$ equals $R\left(\lambda_{2}\right)$ (eq. (2)). Afterwards, the reduced reflectance is integrated within $\lambda_{1}$ and $\lambda_{2}$ in eq. (3) to retrieve TAP.

$$
\begin{aligned}
\lambda_{1} & =\operatorname{argmin}\{R(\lambda)\} & & \text { with } \lambda=[665,680] \\
\lambda_{2} & =\operatorname{argmin}\left\{\operatorname{abs}\left[R\left(\lambda^{\dagger}\right)-R\left(\lambda_{1}\right)\right]\right\} & & \text { with } \lambda \geq 680 \mathrm{~nm} \\
\mathrm{TAP} & =\int_{\lambda_{1}}^{\lambda_{2}}\left[R(\lambda)-R\left(\lambda_{1}\right)\right] d \lambda & &
\end{aligned}
$$

In contrast to $F L H$ retrievals using a spectrally falling baseline, a baseline is computed without slope (eqs. (1) and (2)). The slope of the FLH baseline highly depends on the peak's shape and the surrounding spectrum which can lead to a strong over- or underestimation of fluorescence. However, the TAP is not solely correlated to the fluorescence but also the phytoplankton scattering. The TAP baseline indicated with $L W$ in fig. 2 is only dependent on one free parameter $\lambda_{1}$ and the baseline's spectral length highly varies. Thus, TAP accounts for the changing spectral shape of the peak for different $a 440$.

Additionally, using an interpolation on given simulated wavelengths or sensor bands, i) the accuracy of $\lambda_{2}$ and also TAP is increased, and ii) the number sensor of channels becomes less important.

Section 3 presents the optical model of the Total Algae Peak Integration Retrieval TAPIR which solely depends on optical properties:

$$
\text { TAPIR : } \quad f(T A P, a 440)=c_{0}(T A P) * a 440^{c_{1}(T A P)}=T A P
$$

TAPIR links the combined fluorescence and phytoplankton scattering estimation expressed with TAP retrieved from radiometric signals to a phytoplankton IOP. The coefficients are dependent on the sensor or model (e.g. MOMO simulations or EnMAP) retrieved reflectance peak areas (TAPs). The TAPs vary with the phytoplankton amount and a series of variables in the water and the atmosphere. Table 1 lists a selection that is used in this study.

The technique enables us to retrieve $a 440$ from space-borne, air-borne or in situ reflectance measurements. TAPIR is a fast regional independent algorithm to retrieve the chl-a proxy a440 in optically complex waters. Applying regional bio-optical models for chl-a and $a 440$ from literature [e.g $4,6,40]$ afterwards, a region specific chlorophyll-a concentration can be obtained.

\section{Algorithm sensitivity and uncertainty}

\subsection{Radiative transfer simulation}

The Matrix Operator Model MOMO is an advanced radiative transfer code for multiple applications in coupled atmosphere-water-systems [41-43]. It includes an arbitrary selection of the number of layers, the viewing and sun geometry, the atmospheric conditions, and the state of the water body parameterised by the IOPs from water constituents.

Table 1 summarizes the parameters used in the simulations from $390 \mathrm{~nm}$ to $790 \mathrm{~nm}(\lambda)$ for chlorophyll-a absorption coefficients at $440 \mathrm{~nm}$ from $0.1 \mathrm{~m}^{-1}$ to $10.0 \mathrm{~m}^{-1}$ referring to high a440 


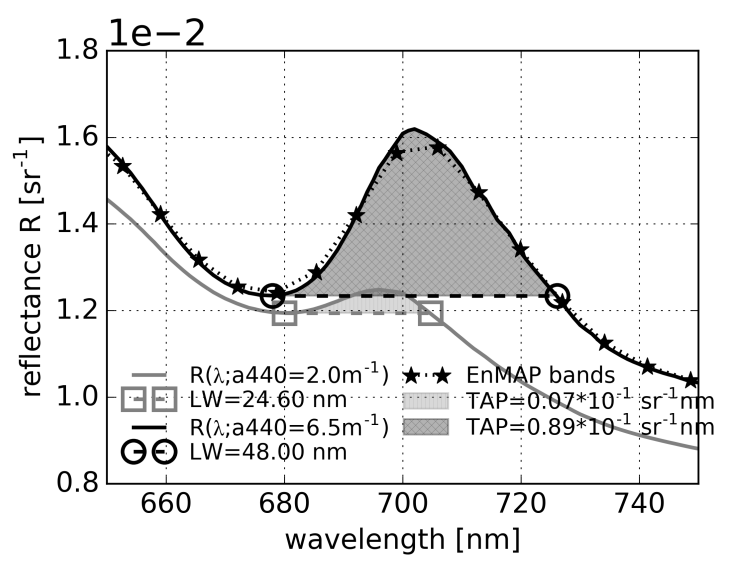

Figure 2. The TAP for two simulated TOA reflectance spectra. The spectral width of the baselines highly differs but $\lambda_{1}$ hardly deviates from $678 \mathrm{~nm}$.

measurements in China [44] and laboratory measurements [45]. In order to investigate the sensitivity of TAPIR, the normalized chlorophyll-a absorption spectrum $\left(a_{p h}\right)$, the aerosol-optical thickness $(a \circ t)$, a spectrally invariant "white" scattering coefficient $(b)$ in the water, the fluorescence quantum yield $\varepsilon$, the single scattering albedo $\omega_{0}$ of phytoplankton at $440 \mathrm{~nm}$, the salinity $s$, the standard atmosphere atm after [46], and the water surface temperature $T_{s}$ are varied.

In MOMO, the extinction coefficient and the corresponding single scattering albedo control the spectral impact of phytoplankton. The reference $\omega_{0}$ at $440 \mathrm{~nm}$ is set to 0.68 to calculate the spectral phytoplankton scattering coefficient depending on the absorption spectrum. Therefore, in MOMO, the magnitude of the chlorophyll-a scattering coefficient $b 440$ scales with $a 440 \cdot \omega_{0}\left(1-\omega_{0}\right)^{-1}$. Increasing a440 increases the spectral absorption scaling the normalized absorption spectrum $a_{p h}$ and increases the spectrally decreasing phytoplankton scattering.

MOMO models the emitted phytoplankton fluorescence near $683 \mathrm{~nm}$ [19] with an exiciation energy based on photosynthetically active radiation (PAR) from $395 \mathrm{~nm}$ to $685 \mathrm{~nm}$, the fluorescence efficiency and the phytoplankton absorption. The additional light from the fluorescence process is attached to the radiation during the radiative transfer simulation.

Based on a collection of in situ measurements [8], MOMO includes a cdom absorption coefficient with $\operatorname{cdom}(a 440,440 \mathrm{~nm})=0.24 * a 440^{0.43}=g(a 440)$ which decreases exponentially towards longer wavelengths with a shape factor of $0.02 \mathrm{~nm}^{-1}$.

The nadir TOA reflectance $R=L_{u} / E_{d}$ is calculated from simulated upwelling radiance $L_{u}$ and downwelling irradiance $E_{d}$ for a sun-zenith angle of $50^{\circ}$ without any atmospheric corrections. $R(a 440)$ are reference spectra defined for section 3 with reference parameters highlighted in table 1.

\subsection{Sensitivity analysis}

Using the MOMO simulations, retrieved reference TOA TAPs are linked with corresponding a440 (solid lines in fig. 3) and the variations of TAP (dashed lines) due to varied parameters $p$ (table 1). According to eq. (4), a power function expresses the TAPs of the TOA reflectance $R=L_{u} / E_{d}$ with a power function:

$$
T A P I R_{\mathrm{ref}}^{\mathrm{TOA}}: \quad \operatorname{TAP}(a 440)=0.0041 * a 440^{1.6171}:=f_{\mathrm{ref}}(a 440) .
$$

The reference TAPIR function $f_{\text {ref }}$ increases linearly with increasing $a 440$ up to $0.2 \mathrm{sr}^{-1} \mathrm{~nm}$ in fig. 3 and for low $a 440$ it is non-linear or zero. 
Table 1. Overview of the parameters varied in the MOMO simulations. Bold values refer to the reference simulation.

\begin{tabular}{lll} 
parameter & range & unit \\
\hline$a 440$ & $0.1,0.5,1.0,1.5,2.0,3.0,5.0,6.5,8.5$ and 10.0 & $\mathrm{~m}^{-1}$ \\
$a_{p h}(\lambda)$ & Doerffer, NechadMIN, NechadMAX (fig. 5a) & $\mathrm{m}^{-1}$ \\
$a o t$ & $0.0, \mathbf{0 . 2}$, and 0.4 & - \\
$b$ & $\mathbf{0 . 0}, 1.0,5.0$, and 10.0 & $\mathrm{~m}^{-1}$ \\
$c d o m$ & $g(a 440), 0.0,1.5$, and 3.0 & $\mathrm{~m}^{-1}$ \\
$\varepsilon$ & $\mathbf{0 . 0 0 3}, 0.01$, and 0.03 & - \\
$\lambda$ & 390 to 790 (with $\Delta \lambda=1 \mathrm{~nm})$ & $\mathrm{nm}$ \\
$\omega_{0}$ & $\mathbf{0 . 6 8}, 0.75$, and 0.82 & - \\
$S$ & 0, and 35 & $\mathrm{PSU}$ \\
$a t m$ & arct. winter, mid.-lat. summer, and tropical & - \\
$S Z A$ & 0,25, 50, and 68 & $\circ$ \\
$T$ & 4.5, and 25 & ${ }^{\circ} \mathrm{C}$
\end{tabular}

In order to estimate the sensitivity of TAPIR, fig. 4 shows the deviations of $f_{\text {ref }}$ with the variation of the parameters. The Jacobians $J_{p}=J_{i j}(p)$ are calculated for TAPIR functions $f_{i}$ with varied parameters $p_{j}$ with eq. (6).

$$
J_{i j}=\frac{\partial f_{i}\left(a 440 ; p_{j}\right)}{\partial p_{j}} \approx \frac{f_{\text {ref }}\left(a 440 ; p_{j, \text { ref }}\right)-f_{i}\left(a 440 ; p_{j, \mathrm{var}}\right)}{p_{j, \mathrm{ref}}-p_{j, \mathrm{var}}}
$$

$\Delta p$ for parameter $a_{p h}$ is computed with the maximum absorption at $670 \mathrm{~nm}$ from the normalized absorption spectra (fig. 5a). Demonstrating the impact of reduced bands, a change in the measurement location, and the standard atmospheres, $\Delta p=1$ applies for EnMAP, BOA, and atm. The Jacobians are non-zero for $i=j$ and the absolute Jacobians generally increase with increasing $a 440$. TAPIR is more sensitive to all of the considered parameters for higher $a 440$.

The sensitivity analysis is grouped in four parts accounting for i) water conditions, ii) atmosphere conditions, iii) phytoplankton parameterisation, and iv) external conditions.

i). In this study, the water conditions vary with the considered parameters $c$ dom, the white scatterer $b$, surface temperature $T$ and salinity $s$ (figs. $3 a$ to $3 d$ ). In contrast to the blue-green ratio proxy estimating $c h l-a$, the spectral range of the fluorescence is nearly invariant to $c d o m$ absorption and, therefore, a negligible dependence on the TAPs is expected.

The in-water parameters have a minor impact on TAPIR due to Jacobians less than two orders of magnitude than the reference TAPs (figs. 4 a to $4 \mathrm{~d}$ ).

The TAPs are slightly sensitive to $c d o m$ with Jacobians less than three orders of magnitude. However, the impact of $c$ dom is less than the influence of the scatterer $b$. "White" scatterers (e.g. sediments) brightens the total visible reflectance spectrum and, therefore, slightly enlarge the peak due to a higher available fluorescence excitation energy and increased total scattering. Salinity and surface temperature are negligible.

Therefore, TAPIR is applicable for all kind of waters including case- 1 and case- 2 , coastal and inland waters, and regions with high or low sea surface temperature.

ii). Figures $3 \mathrm{e}$ and $3 \mathrm{f}$ display the impact of varying standard atmosphere conditions $\mathrm{atm}$ and aerosol optical thickness aot. A change in the atmospheric vertical temperature and pressure distribution results in a low sensitivity on the atmosphere structure with Jacobians below $10^{-5}$ (fig. 4e).

In fig. $4 \mathrm{f}$, an increasing aot diminishes the TAPs linearly with increasing a440 due to less available light for the fluorescence process and absorption of the upwelling signal in the atmosphere. Unfortunately, the sensitivity on aot ranges in the same magnitude of the reference TAPIR function and, therefore, aot must be considered in the retrieval. 

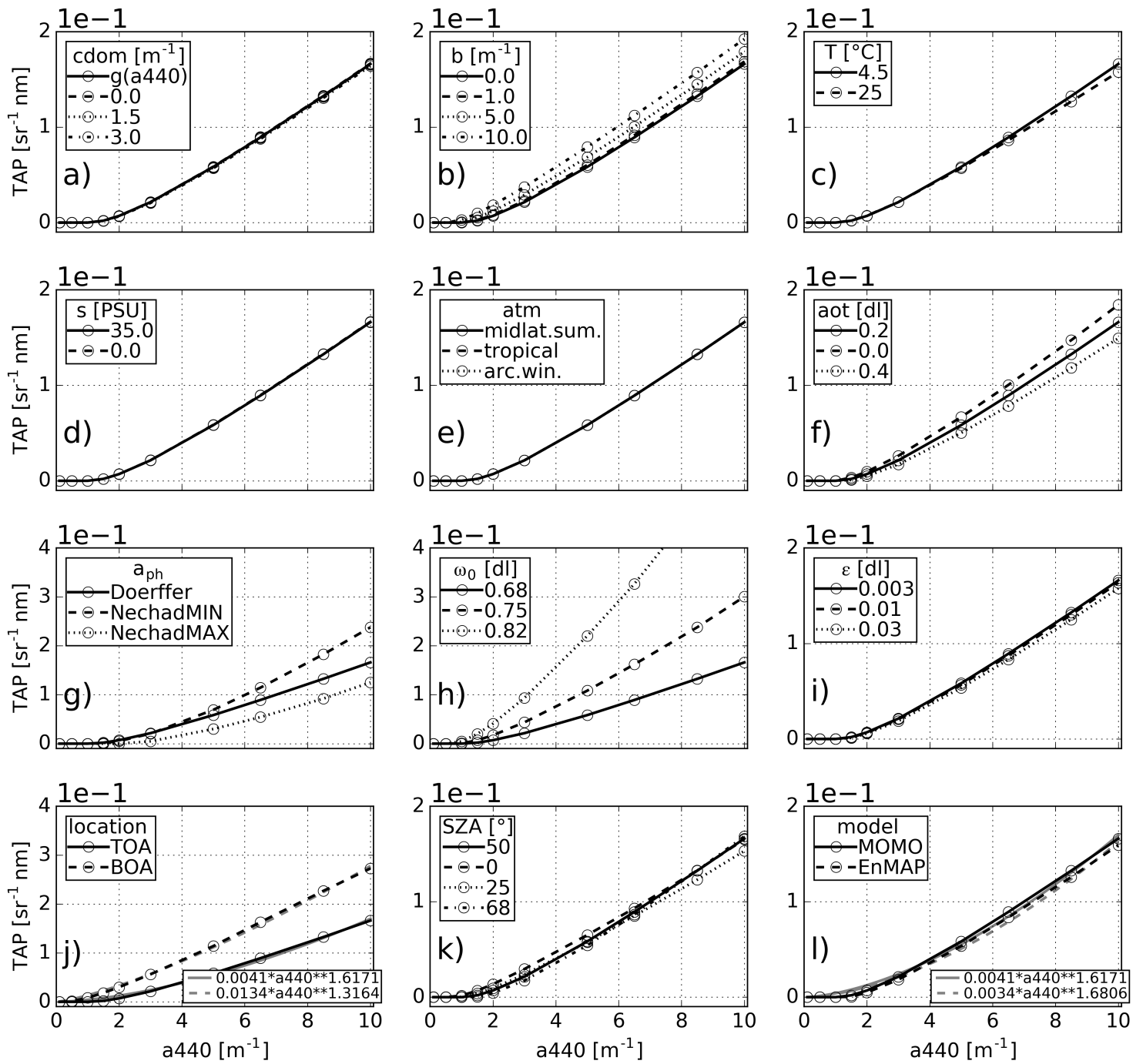

Figure 3. Retrieved TAPs over $a 440$ and their variants due to adjusted simulation parameters (table 1). The solid lines link the TAPs computed from reference simulations from which the TAPIR function in eq. (5) is calculated.

iii). MOMO parameterises phytoplankton using a given normalised phytoplankton absorption spectrum scaled with the spectral extinction coefficients and the corresponding single scattering albedo (section 3.1). Figure 5 illustrates variations of chlorophyll-a absorption spectra $a_{p h}(\lambda)$ normalized at $440 \mathrm{~nm}$ and the corresponding single scattering albedo $\omega_{0}$ for constant values of $0.68,0.75$ and 0.82 at $440 \mathrm{~nm}$. In this study, varying $\omega_{0}$ solely changes the ratio of phytoplankton scattering and absorption. The current absorption coefficient remains equal whereas the phytoplankton scattering coefficient increases or decreases, respectively. Thus, an increasing $\omega_{0}$ induces an increased extinction coefficient.

The spectra NechadMIN and NechadMax are averaged from normalized HydroLight absorption spectra [8] for the ranges from $0.2 \mathrm{~m}^{-1}$ to $0.3 \mathrm{~m}^{-1}$ for $a_{p h}(670 \mathrm{~nm})$ and $0.7 \mathrm{~m}^{-1}$ to $0.8 \mathrm{~m}^{-1}$, respectively. They vary in magnitude and width of the local absorption maximum at $670 \mathrm{~nm}$ and the spectral shape (e.g in the blue visible range in fig. 5a).

TAPIR is strongly sensitive to the underlying absorption spectrum (figs. $3 g, 4 g$ and $5 \mathrm{a}$ ). The lower the absorption spectrum beyond $550 \mathrm{~nm}$ the faster rises the slope of the TAPIR function with increasing a440 due to an increased scattering (fig. 5b). 

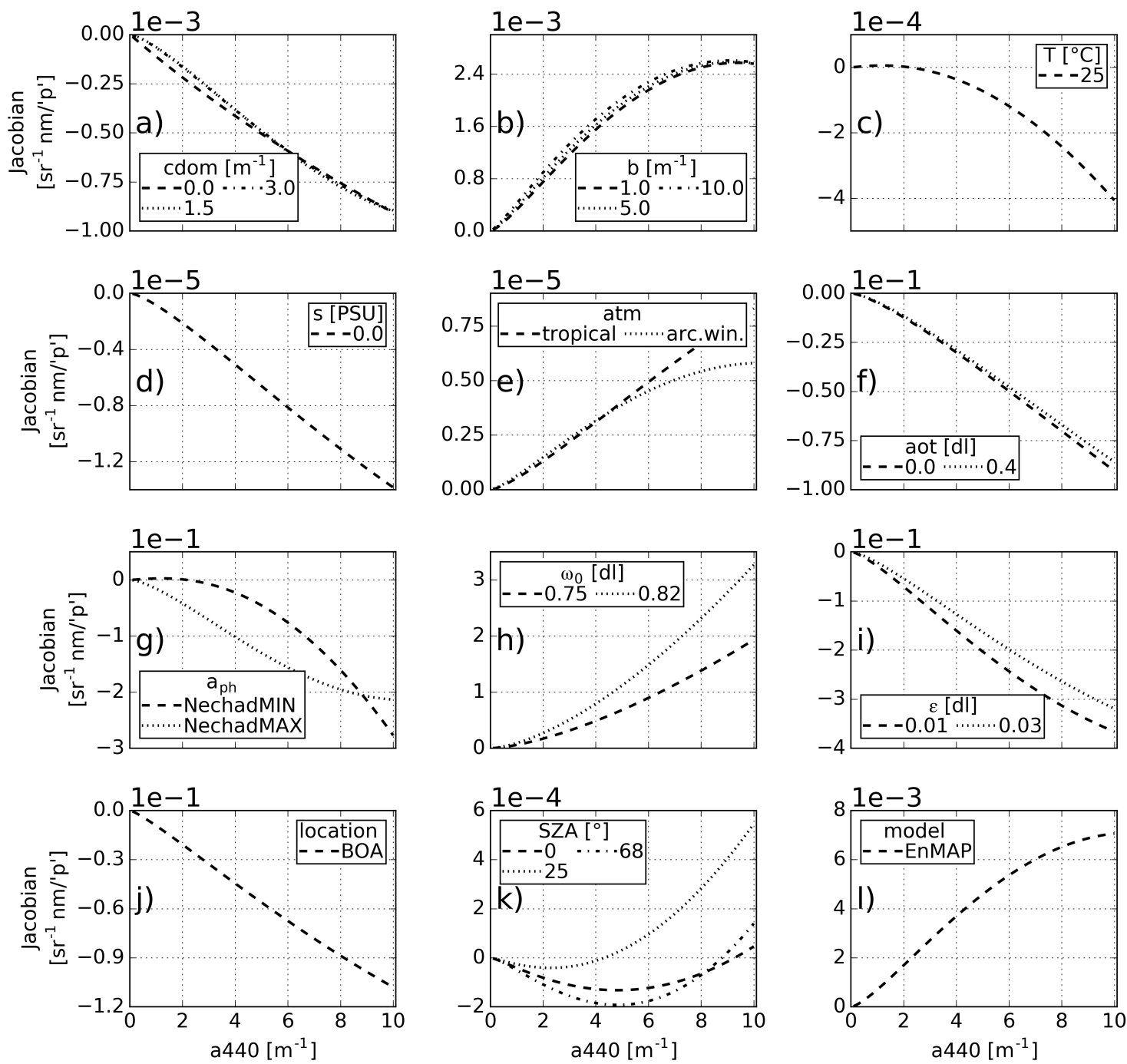

Figure 4. Jacobians of the reference TAPIR function $f_{\text {ref }}$ (eqs. (5) and (6)) calculated from simulations with the reference parameters emphesised in table 1 per 9440 . Note the different ordinate scales and magnitudes which represent the sensitivity.

An increase of phytoplankton scattering of either a reduced absorption spectrum or an increased single scattering albedo (e.g. NechadMIN and $\omega_{0}=0.75$, respectively) can double the retrieved TAP for high $a 440$ (figs. $3 \mathrm{~g}$ and $3 \mathrm{~h}$ ). Strong phytoplankton scattering $\left(\omega_{0}=0.82\right)$ increases the TAP by more than a factor 3 (figs. 3h and $4 \mathrm{~h}$ ).

Accounting for the fluorescence efficiency $\varepsilon$, figs. $3 j$ and $4 j$ reveal a strong impact on the retrieved TAPs mainly depending on the competitive impact of the effective fluorescence peak shifting towards shorter wavelength for increasing $\varepsilon$ and an increasing redshift for increasing $a 440$.

Therefore, the major TAPIR sensitivity originates from the phytoplankton's IOPs and bio-physical condition whereas phytoplankton scattering is the main impacting factor.

iv). The measurement location (TOA or bottom of the atmosphere (BOA)), the sun zenith angle (SZA), and the number of available sensor bands are external Referring to conditions which can be considered before defining a TAPIR function. The functions for BOA and TOA in fig. $3 j$ highly differ due to Rayleigh scattering and the atmospheric interaction. A changing $S Z A$ slightly influences the 

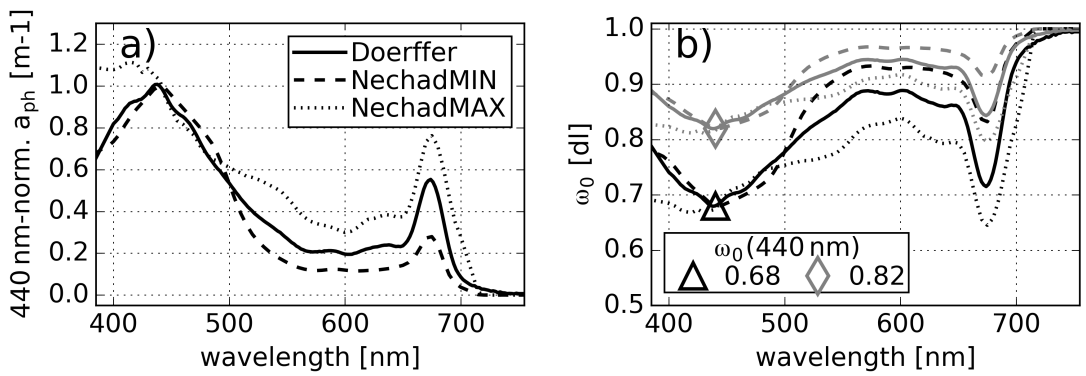

Figure 5. Variation of a) the phytoplankton absorption spectrum (normalised to $a_{p h}(440 \mathrm{~nm})$ ) and b) the corresponding single scattering albedo for $\omega_{0}(440 \mathrm{~nm})=0.68$ (reference) and 0.82 (grey). The black solid lines illustrate the reference spectra and the dashed lines the variations collected from HydroLight simulations by [8].

Table 2. List of variables $x$ and their $\sigma_{x}$ used in the uncertainty calculation in eq. (9). Exemplaryly, the table presents the summands of eq. (9) $\left[\left(\mathrm{m}^{-1}\right)^{2}\right]$ for $a 440$ of $2.0 \mathrm{~m}^{-1}$ and $6.5 \mathrm{~m}^{-1} . \sigma_{\text {TAP }}$ depends on a440. The variables $c_{0}$ and $c_{1}$ exhibit the units [ $\left.\mathrm{sr}^{-1} \mathrm{~nm} \mathrm{~m}\right]$ and [dl], respectively.

\begin{tabular}{llll}
\hline$x$ & $\sigma_{x}$ & $\left(\partial_{x} f^{-1}\left(x\left(2.0 \mathrm{~m}^{-1}\right)\right) \sigma_{x}\right)^{2}$ & $\left(\partial_{x} f^{-1}\left(x\left(6.5 \mathrm{~m}^{-1}\right)\right) \sigma_{x}\right)^{2}$ \\
\hline$c_{0}$ & $6.366 \cdot 10^{-4}$ & $3.690 \cdot 10^{-2}$ & $3.898 \cdot 10^{-1}$ \\
$c_{1}$ & $7.203 \cdot 10^{-2}$ & $3.812 \cdot 10^{-3}$ & $2.936 \cdot 10^{-1}$ \\
TAP & $5.192 \cdot 10^{-3}$ & $2.638 \cdot 10^{-1}$ & - \\
TAP & $3.070 \cdot 10^{-2}$ & - & 2.129 \\
\hline
\end{tabular}

slope of the TAPIR function (fig. 3k) but due to low Jacobians in fig. 4k the impact of SZA can be assumed to play a minor role.

For EnMAP applications, the $1 \mathrm{~nm}$-resolved MOMO simulations are convolved to 15 EnMAP bands within $650 \mathrm{~nm}$ to $750 \mathrm{~nm}$ (fig. 2). A reduction to a lower band resolution for EnMAP reduces the TAPs with increasing $a 440$ because the original area is not entirely reproduced (figs. 2 and 31). However, the sensitivity on reducing the number of bands to EnMAP specifications ranges below two orders of magnitude of the reference TAPs.

Uncertainties concerning the location, radiometric resolution (EnMAP), or the sun zenith angle can be avoided by developing separate TAPIR functions. For further use, fitted functions (figs. $3 \mathrm{j}$ and 31) for bottom of atmosphere (BOA) applications and for EnMAP at top of the atmosphere are provided:

$$
\begin{aligned}
\text { TAPIR }_{\mathrm{BOA}}: & \text { TAP }(a 440)=0.0134 * a 440^{1.3164} \\
\text { TAPIR }_{\text {EnMAP }}: & \text { TAP }(a 440)=0.0034 * a 440^{1.6806}
\end{aligned}
$$

In conclusion, TAPIR is mainly sensitive to a440 and the phytoplankton optical properties (single scattering albedo, the underlying absorption spectrum, and the efficiency), which suggests the opportunity of distinguishing different phytoplankton types. The application of various phytoplankton type dependent absorption spectra may result in variants in TAPIR due to slightly shifted absorption maxima and intensities. Unfortunately, the aot influence cannot be neglected due similar magnitudes of the TAPIR function and the corresponding Jacobians and must be considered with an atmospheric correction. 
Table 3. List of parameters used in the uncertainty estimation in eq. (10). The deviation's denominator $\Delta p$ is computed with $p_{v a r}$ and $p_{\text {ref }}$ and use a reasonable conservative $\sigma_{p}$ from literature (column "ref.") or assume it. Table 1 lists their units. Exemplary, the table presents the summands of eq. (10) $\left[\left(\mathrm{sr}^{-1} \mathrm{~nm}\right)^{2}\right]$ per parameter for $a 440$ of $2.0 \mathrm{~m}^{-1}$ and $6.5 \mathrm{~m}^{-1} . \sigma_{\text {atm }}$ is set to 1 because the parameter $a t m$ contains vertical atmospheric profiles. The values of $p_{r e f}$ and $p_{v a r}$ for parameter $a_{p h}$ are the $670 \mathrm{~nm}$ coefficients of the normalised absorption spectra "Doerffer" and "NechadMIN". The parameters $\lambda_{1}$ and $\lambda_{2}$ depend on the selected reflectance spectrum and vary with $a 440$. The deviation is estimated by small variations of $\pm 1 \mathrm{~nm}$ and assume a $\sigma_{\lambda}$ of $1 \mathrm{~nm}$.

\begin{tabular}{lcccccc}
\hline$p$ & $p_{\text {ref }}$ & $p_{\text {var }}$ & $\sigma_{p}$ & ref. & $\left(\partial_{p} T A P\left(2.0 \mathrm{~m}^{-1}\right) \sigma_{p}\right)^{2}$ & $\left(\partial_{p} T A P\left(6.5 \mathrm{~m}^{-1}\right) \sigma_{p}\right)^{2}$ \\
\hline cdom & $g(a 440)$ & 0.000 & 0.050 & {$[47]$} & $1.187 \cdot 10^{-10}$ & $1.006 \cdot 10^{-9}$ \\
$b$ & 0.000 & 1.000 & 0.150 & {$[48]$} & $1.260 \cdot 10^{-8}$ & $1.153 \cdot 10^{-7}$ \\
$T$ & 4.500 & 25.000 & 1.500 & {$[49]$} & $1.052 \cdot 10^{-11}$ & $4.767 \cdot 10^{-8}$ \\
$s$ & 35.000 & 0.000 & 0.002 & {$[50]$} & $1.823 \cdot 10^{-17}$ & $3.164 \cdot 10^{-16}$ \\
$a t m$ & midlat & arcwin & 1.000 & - & $1.705 \cdot 10^{-12}$ & $2.895 \cdot 10^{-11}$ \\
aot & 0.200 & 0.000 & 0.070 & {$[51]$} & $7.407 \cdot 10^{-7}$ & $1.476 \cdot 10^{-5}$ \\
$a_{p h}$ & 0.533 & 0.273 & 0.020 & {$[52]$} & $3.136 \cdot 10^{-10}$ & $3.546 \cdot 10^{-6}$ \\
$\omega_{0}$ & 0.680 & 0.750 & 0.050 & - & $2.636 \cdot 10^{-5}$ & $9.218 \cdot 10^{-4}$ \\
$\varepsilon$ & 0.003 & 0.010 & 0.005 & - & $1.259 \cdot 10^{-7}$ & $1.718 \cdot 10^{-6}$ \\
$\lambda_{1}$ & $\lambda_{1}(a 440)$ & $\lambda_{1} \pm 1 \mathrm{~nm}$ & 1.000 & - & $2.292 \cdot 10^{-8}$ & $3.037 \cdot 10^{-7}$ \\
$\lambda_{2}$ & $\lambda_{2}(a 440)$ & $\lambda_{2} \pm 1 \mathrm{~nm}$ & 1.000 & - & $1.359 \cdot 10^{-9}$ & $7.201 \cdot 10^{-9}$ \\
\hline
\end{tabular}

\subsection{Uncertainty Assessment}

TAPIR supports the estimation of the phytoplankton amount proxy $a 440$. Thus, the reference TOA TAPIR function from eq. (4) is inverted to $f^{-1}$ and an uncertainty propagation for $a 440$ is conducted. Assuming uncorrelated variables, eq. (9) computes the uncertainty $\sigma_{a}$. The deviation of $f^{-1}$ depends on $i=3$ variables $x$ : The fitting coefficients $c_{0}$ and $c_{1}$ and the TAP per $a 440$.

$$
\sigma_{a}^{2}=\sum\left(\frac{\partial f^{-1}\left(x_{i}\right)}{\partial x_{i}} \sigma_{x_{i}}\right)^{2}
$$

Equation (9) is determined $\partial_{x} f^{-1}(x)$ analytically. Fitting the simulated TOA TAPs to the input a440 in section 3.2, the coefficients $c_{0}$ and $c_{1}$ are empirically retrieved and simultaneously the standard deviations $\sigma_{\mathcal{c}_{0}}$ and $\sigma_{\mathcal{c}_{1}}$ are obtained and listed in table 2 .

The uncertainty $\sigma_{a}$ additionally depends on the accuracy of the TAP computation with eq. (3). The TAP deviates with varied parameters from table 1 and the selection of the integration limits $\lambda_{1}$ and $\lambda_{2}$. The parameters $S Z A$, number of measurement bands (e.g. EnMAP), and the measurement location (e.g. at the surface (BOA)) are excluded because they can be considered previously to the TAPIR function development. The TAP uncertainty $\sigma_{T A P}$ for $j$ parameters $p$ is computed with eq. (10) .

$$
\sigma_{T A P}^{2}=\sum\left(\frac{\partial T A P\left(p_{j}\right)}{\partial p_{j}} \sigma_{p_{j}}\right)^{2} \approx \sum\left(\frac{\Delta T A P\left(p_{j}\right)}{\Delta p_{j}} \sigma_{p_{j}}\right)^{2}
$$

The summands of eq. (10) $\partial_{p_{j}}$ TAP are numerically estimated. Therefore, the difference between $\operatorname{TAP}\left(p_{j, r e f}\right)$ and $\operatorname{TAP}\left(p_{j, v a r}\right)$ is calculated to retrieve $\triangle \operatorname{TAP}\left(p_{j}\right)$. The values of the reference and variation of the parameters, $p_{\text {ref }}$ and $p_{v a r}$, are listed in table 3 . The reference value for $c d o m$ is dependent on $a 440$ with $g(a 440)$ in section 3.1 and for $a_{p h}$ we extract the $670 \mathrm{~nm}$ absorption coefficient from the normalised spectra "Doerffer" and "NechadMIN" (fig. 5a). 

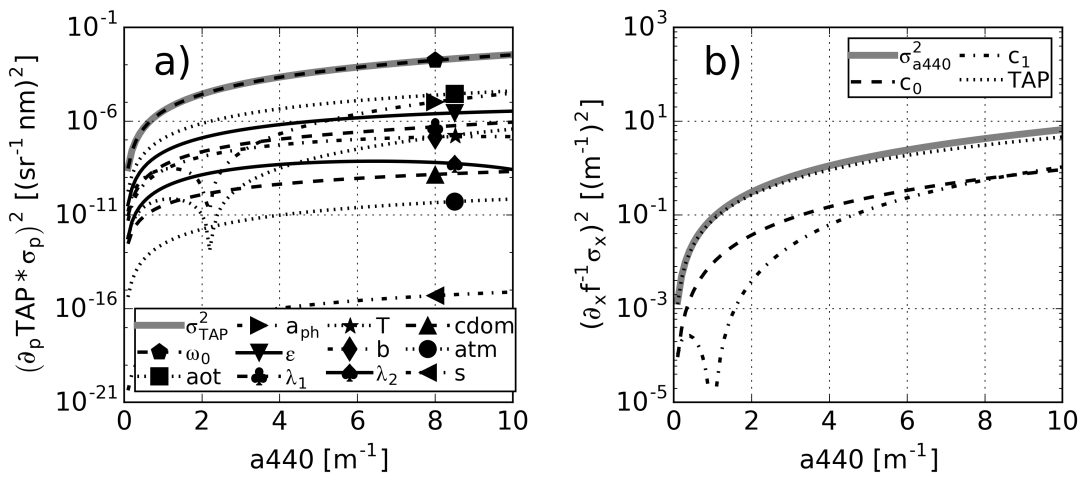

Figure 6. Summands of eq. (10) (black lines with markers indicating the parameter) and $\sigma_{T A P}^{2}$ (grey line) in panel a). Panel b) shows the summands of eq. (9) (black) and the final $\sigma_{a}^{2}$ (grey). The squared uncertainties relate to the values listed in tables 2 and 3.

The deviation $\Delta p_{j}$ is the difference between parameter $p_{j, r e f}$ and its variation $p_{j, v a r}$. We set $\Delta p_{a t m}$ to 1 because the parameter atm contains vertical profiles. We conservatively choose parameter dependent uncertainties $\sigma_{x}$ from literature or assume reasonable values.

Figure 6a illustrates the $\sigma_{T A P}^{2}$ summands (black lines) from eq. (10) which exponentially increase with increasing $a 440$. The final $\sigma_{\text {TAP }}^{2}$ (thick grey line) mainly consists of the variation of $\omega_{0}$. The "spikes" near $2.0 \mathrm{~m}^{-1}$ appear due to the logarithmic presentation and a local minimum close to zero. Using different $p_{j, v a r}$, they shift or disappear.

Analogous, fig. $6 \mathrm{~b}$ shows the $\sigma_{a}^{2}$ summands (black lines) from eq. (9) and the final squared uncertainty for $a 440$ (grey) which mainly consists of the variation of TAP. Therefore, the accuracy of a440 primarily depends on the parameterisation of phytoplankton.

Generally, $\sigma_{a}^{2}$ increases exponentially with increasing a440 and ranges from approximately $10^{-3} \mathrm{~m}^{-2}$ to $10^{1} \mathrm{~m}^{-2}$. Unfortunately, $\sigma_{a}$ is rather large and ranges in the magnitude of $a 440$. Exemplary, an uncertainty $\sigma_{a}$ of $0.55 \mathrm{~m}^{-1}$ and $1.68 \mathrm{~m}^{-1}$ for $a 440$ of $2.00 \mathrm{~m}^{-1}$ and $6.50 \mathrm{~m}^{-1}$ is retrieved. The uncertainty is less than $30 \%$ of $a 440$ for absorption coefficients greater than $0.8 \mathrm{~m}^{-1}$ and less than $38 \%$ for the entire $a 440$ range from $0.1 \mathrm{~m}^{-1}$ to $10.0 \mathrm{~m}^{-1}$. For BOA and EnMAP applications, the $a 440$ uncertainty ranges from $17 \%$ to $20 \%$ and $25 \%$ to $40 \%$, respectively.

\section{Validation}

\subsection{Measurement dataset}

For first validation efforts in section 4.2, datasets collected by Nechad et al. [8] are used. They provide hyperspectral in situ measurements at the North Sea (NoS) and in Indonesian waters (InW) among other locations. Besides various IOPs and apparent optical properties (AOPs), each set contains spectral phytoplankton absorption coefficients $a_{p h}(\lambda)$ and irradiance reflectance converted to remote sensing reflectance $R_{R S}$.

Unfortunately, the $a_{p h}(\lambda)$ and $R_{R S}$ have not been measured simultaneously for InW and NoS and $a 440$ is computed from the available measured chl-a. Fortunately, some different measurement stations in the North Sea provide matching $a 440$ and chl-a measurements [8] and an empirical bio-optical model $a 440=(0.040 \pm 0.004) *$ chl-a $a^{(0.850 \pm 0.108)}$ could be developed .

\subsection{Validation assessment}

In fig. 7 in situ measurements of the North Sea (NoS) and Indonesian Waters (InW) are compared with the retrieved TAPIR function at the surface (eq. (7)) for preliminary validation 

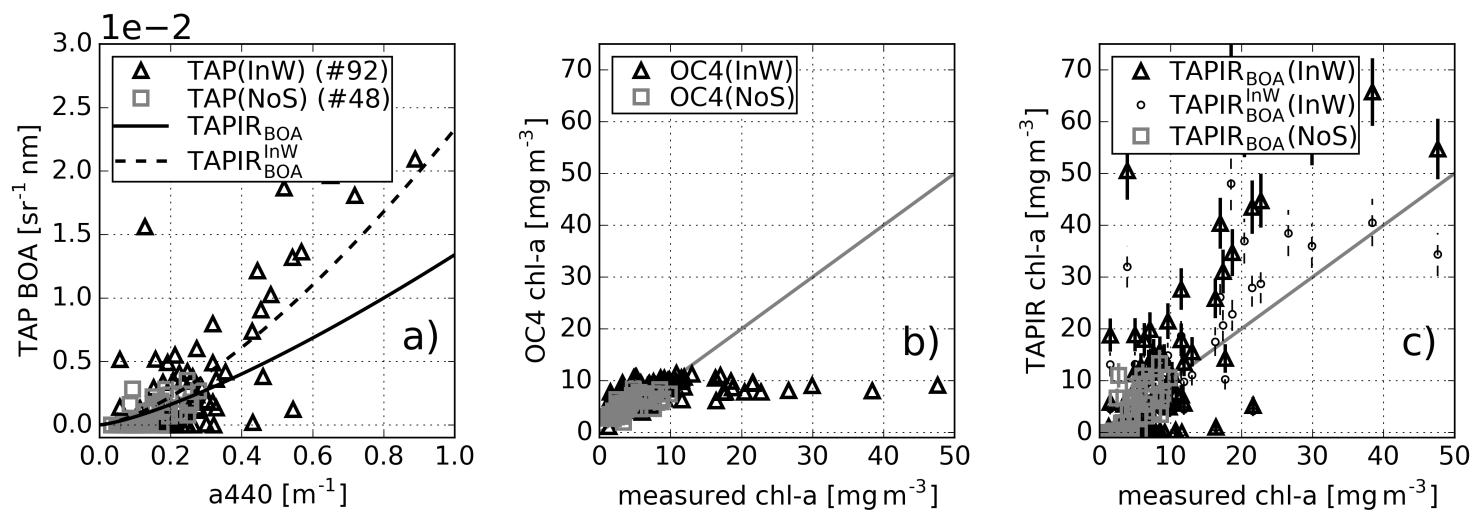

Figure 7. TAPs of surface measurements at the North Sea (NoS) and in Indonesian waters (InW) collected from [8] and the functions TAPIR $\mathrm{BOA}_{\mathrm{BOA}}$ and TAPIR $\mathrm{InOA}_{\mathrm{BOA}}^{\mathrm{InW}}$ (eqs. (7) and (11)) in a). Panels b) and c) show the performance of the OC4 and the TAPIR retrievals. The vertical bars in panel c) represent calculated uncertainties for BOA applications. The circle markers with the thin dashed bars show chl- $a$ estimated from the empirical TAPIR $\mathrm{BnOA}$ function (dashed line in panel a) and eq. (11)) with a raised slope based on the TAPs from InW in a).

efforts. Unfortunately, the measurements only provide re-calculated a440 (see section 4.1) up to $1 \mathrm{~m}^{-1}$. However, the calculated TAPs from measured hyperspectral reflectance spectra are closely located to the retrieved TAPIR $R_{\mathrm{BOA}}$ function (black solid line in fig. 7a).

In fig. 7a, there are 55 of 92 and 25 of 48 zero TAPs of InW (grey squares) and NoS (black triangles), respectively, within $a 440$ from $0.0 \mathrm{~m}^{-1}$ to $0.4 \mathrm{~m}^{-1}$, due to an unapparent peak in the reflectance spectra. Chl- $a$ and additionally provided measurements of total suspended matter (TSM) range within $0.8 \mathrm{mg} \mathrm{m}^{-3}$ to $50 \mathrm{mg} \mathrm{m}^{-3}$ and $0 \mathrm{~g} \mathrm{~m}^{-3}$ to $200 \mathrm{~g} \mathrm{~m}^{-3}$, respectively.

The zero TAPs occur for TSM and chl-a measurements within $0 \mathrm{~g} \mathrm{~m}^{-3}$ to $50 \mathrm{~g} \mathrm{~m}^{-3}$ and $0.8 \mathrm{mg} \mathrm{m}^{-3}$ to $10 \mathrm{mg} \mathrm{m}^{-3}$, respectively. A combination of low chl-a $\left(<10 \mathrm{mg} \mathrm{m}^{-3}\right)$ and the occurrence of non-phytoplankton TSM may result in an unapparent peak. However, there are measurements of similar conditions with an apparent peak and non-zero TAP.

$12 T A P(\operatorname{InW})$ are remarkably raised compared to TAPs expected from sthe TAPIR $R_{\mathrm{BOA}}$ function (black line). Increased scattering for high amounts of TSM $\left(>70 \mathrm{~g} \mathrm{~m}^{-3}\right)$ and chlorophyll-a $\left(>17 \mathrm{mg} \mathrm{m}^{-3}\right)$ can be assumed to raise the peak and the corresponding TAP. However, as outlined in section 3.2 and section 3.3, the phytoplankton parameterisation in the simulations mainly impacts the TAPIR. A raised portion of non-phytoplankton TSM, a tight packaging of phytoplankton chloroplasts, and the cell walls itself can cause an increased scattering which may increase the magnitude of the peak. Therefore, an empirical TAPIR function (eq. (11)) based on the TAPs in the Indonesian Waters (dashed black line in fig. 7a) is developed. The slope of the function is raised compared to the BOA function.

$$
\text { TAPIR } \mathrm{BOA}: \quad \operatorname{TAP}(a 440)=0.023 * a 440^{1.1463}
$$

Applying the ocean colour algorithm OC4 [12] in fig. 7b, the retrieved OC4 chl-a match up with the measured chl- $a$ for less than $10 \mathrm{mg} \mathrm{m}^{-3}$ which borders the upper definition limit. The OC4 chl- $a$ remains stable near $10 \mathrm{mg} \mathrm{m}^{-3}$ for measured chl-a beyond $10 \mathrm{mg} \mathrm{m}^{-3}$ due to the presence of additional OACs.

The chl- $a$ retrieved from TAPIR (triangles and squares with error bars in fig. 7c) is blurrier than the OC4 chl-a for chl-a measurements below $10 \mathrm{mg} \mathrm{m}^{-3}$ but still exhibits a good estimation. For larger chl-a, TAPIR overestimates chl- $a$ with the current TAPIR $R_{\mathrm{BOA}}$ from eq. (7) but in contrast to OC4, TAPIR is able 
to reproduce higher chl- $a$ according to the 1:1 line. The maximum $a 440$ for this data set is less than $1 \mathrm{~m}^{-1}$ and section 3.3 shows higher uncertainties for absorption coefficients below $0.8 \mathrm{~m}^{-1}$. However, TAPIR reproduces sufficient chl-a estimations for the North Sea (grey squares in fig. 7c).

Applying the empirical TAPIR $R_{\mathrm{BOA}}^{\mathrm{InW}}$ function (eq. (11) and dashed line in fig. 7a), the retrieved TAPIR chl-a (bullets with dashed error bars) in fig. 7c closely approach the 1:1 line.

The deviation from measured chl-a may occur due to the following issues. The TAPIR function in eq. (7) is developed with the reference parameters for the surface. Applying a different phytoplankton parameterisation (e.g. $a_{p h}=$ NechadMIN) or additional features considering scattering by non-phytoplankton matter, may improve the chl-a accuracy with TAPIR. Increasing the parameters

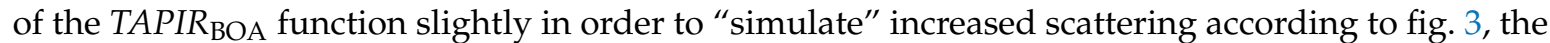
chl-a estimations for InW approach the 1:1 line.

In order to assign the retrieved TAPs to $a 440$ in fig. 7a, it was necessary to convert the measured chl-a to $a 440$ applying a bio-optical model which likely adds additional uncertainties.

However, we highly recommend TAPIR for usage in optically complex waters due to the ability to retrieve low and high $c h l-a$ in the presence of additional OACs.

\section{Discussion}

In an algae cell, the processes photosynthesis, dissipation, and fluorescence antagonistically consume the energy of absorbed photons. Nevertheless, fluorescence can also occur in deceased phytoplankton but the aquatic community mainly focuses on living cells. Thus, measuring the fluorescence, the amount of chlorophyll-a and the living activity can be estimated. The estimation and interpretation of fluorescence remain still complex because an increase in fluorescence occurs either due to more chl-a or the reduction of one or both of the other processes. Among others, the fluorescence process depends on the algae type, physiology, health, and environmental conditions. The study focuses on an increase of fluorescence due to an increase of chl- $a$ and $a 440$, respectively.

However, the peak near $683 \mathrm{~nm}$ does not solely occur due to fluorescence but is mainly induced by phytoplankton scattering. Therefore, in contrast to $F L H$ retrievals claiming results of pure fluorescence, investigating the reflectance peak within the fluorescence range from $670 \mathrm{~nm}$ to $700 \mathrm{~nm}$, both the fluorescence and the algae scattering is obtained. Phytoplankton absorption influences and scales both properties.

Section 3 demonstrates the applicability of TAPIR which is influenced by various parameters (see table 1). TAPIR provides advantages by "catching" the total effective peak with its variable magnitude, location, and shape.

In contrast to FLH, TAPIR exhibits a monotonically increasing slope with increasing a440 and chl-a, respectively, obviating ambiguous $a 440$ and assimilates to the natural behaviour of the effective peak by avoiding constant measurement bands. Of course, TAPIR requires a minimum number of bands for a proper integration whereas EnMAP specifications promise sufficient results. The minimum number has to be investigated for a pre-defined acceptance uncertainty.

Providing specific TAPIR functions for several external conditions (number of bands, SZA, TOA/BOA), we can use these globally in inland and coastal waters and open oceans due to the insensitivity to salinity, temperature, and pressure.

Considering the atmospheric parameters atm and aot, the simulated TAPs and the TAPIR sensitivity promise a neglection of the vertical temperature and pressure distribution in the atmosphere. However, the impact of strongly absorbing gases in the visible could have been underestimated. Therefore, water vapour, ozone, and oxygen should be considered sensitively in future studies. Unfortunately, the impact of aot ranges in similar magnitudes of the phytoplankton properties and may not be neglected. Nevertheless, future studies may reveal a constant linear relation (fig. $4 \mathrm{f}$ ) which can support a simple correction of the TOA signals required for TAPIR. For BOA applications, aot is less important.

In the water, only the upper $3 \mathrm{~m}$ to $5 \mathrm{~m}$ can be described because the water absorption in the red visible spectrum is rather strong and the radiometric signal maximum depth is limited. However, in 
optically complex waters with a contribution of $c d o m$, the penetration depth is limited to a few meters even in the blue spectrum.

Sediments and cdom hardly influence TAPIR and it is applicable to optically complex waters. TAPIR mainly depends on the phytoplankton IOPs producing the highest uncertainties and largest sensitivities. Further investigations of phytoplankton type specific measurements accounting for chlorophyll-a absorption spectra, scattering spectra, the phase function, and the efficiency factor support the parameterisation of phytoplankton in optical models. This might be an opportunity for retrievals based on TAPIR to obtain phytoplankton types or the fluorescence exclusively.

On the one hand, the fluorescence depends on the phytoplankton condition and properties and on the other hand on the available fluorescence excitation energy from the ambient light field. The presence of aquatic and atmospheric constituents change the amount of light available for the absorption which directly changes the amount of available excitation energy for fluorescence. The magnitude of reduction depends on the parameter whereas the selection of the fluorescence efficiency $\varepsilon$ can mainly control the magnitude, shape, and location of the effective fluorescence peak. Assuming ideal conditions (clear atmosphere, little water constituents) and a low $\varepsilon$ (maybe due to the physiological condition of algae), the fluorescence can be smaller than expected. Therefore, it is important to consider the sensitivity and uncertainty of all parameters on the reflectance of the entire visible spectrum although they may have little impact on the fluorescent spectrum around $683 \mathrm{~nm}$. A retrieval considering the redshift, which increases with decreasing $\varepsilon$ but increasing $a 440$, might be able to obtain reference values of $\varepsilon$.

Quantifying the fluorescence and also phytoplankton scattering with TAP, the selection of the lower integration limit $\lambda_{1}$ depends on the available signal bands near $670 \mathrm{~nm}$. $\lambda_{1}$ constrains the integration and can influence the final TAP due to the definition of the "reflectance constant" $R\left(\lambda_{1}\right)$, which reduces the total reflectance, and the upper integration limit $\lambda_{2}$. The impact of $\lambda_{1}$ has to be considered but, usually, most of the sensors (e.g. EnMAP) have a less radiometric resolution than MOMO which limits the choice of $\lambda_{1}$ to 1 or 2 possible bands. Therefore, developing sensor specific TAPIR functions from simulations relativises the relation between TAP and $a 440$ among each other.

Accounting for sensors with fewer bands than EnMAP (e.g. Hyperion or OLCI with 10 and 5 bands within $660 \mathrm{~nm}$ to $750 \mathrm{~nm}$, respectively), the peak could be estimated with a fitting function. Unfortunately, the absorption properties of phytoplankton and water highly influence the peak's shape which complicates the application of a unique function (e.g. Gauß). However, it is necessary to study the change of sensitivities and uncertainties of the TAPs for all parameters, which might highly differ, for a function describing the fluorescence peak.

The uncertainties retrieved in this study are within $25 \%$ to $38 \%$ of the phytoplankton absorption $a 440$ and are dependent on $a 440$ itself. Considering different parameter values and parameter uncertainties $\sigma_{p}$, they likely change. The assumption of the $\sigma_{p}$ particularly influences the final $a 440$ uncertainty $\sigma_{a 440}$. Nevertheless, a first validation assessment reveals sufficient results for TAPIR retrieved $a 440$ and chl-a, respectively.

\section{Conclusions}

This study indroduces the Total Algae Peak Integration Retrieval TAPIR which links the phytoplankton induced reflectance peak near $683 \mathrm{~nm}$ with chlorophyll-a absorption at $440 \mathrm{~nm}(a 440)$. Firstly, the peak loacted near 683nm induced by chlorophyll-a fluorescence and phytoplankton scattering is quantified with an integration (TAP). Secondly, a TAPIR function is developed for top of the atmosphere (TOA) simulated data depending on $a 440$. Afterwards, the inverse of the function provides the possiblity to retrieve $a 440$ from reflectance data. Therefore, TAPIR and its functions support relation to phytoplankton absorption, scattering, fluorescence, and the concentration.

Sensitivity studies on various atmospheric and aquatic parameters reveal a major dependence on the parameterisation of phytoplankton (IOPs and fluorescence efficiency factor), some aerosol influence, and little impact on water constituents. 
TAPIR applies to all kind of waters relating to optical complexity, geographical location, measurement location, and water constituents. The uncertainty of a440 from TOA signals is approximately $30 \%$ (e.g. $(2.00 \pm 0.55) \mathrm{m}^{-1}$ and $\left.(6.50 \pm 1.68) \mathrm{m}^{-1}\right)$.

The simulations for EnMAP specific conditions are promising for an accurate fluorescence and chl-a retrieval and studies can benefit from a high spatial resolution $(30 \mathrm{~m})$.

Acknowledgments: We thank the DLR (Deutsche Luft- und Raumfahrt) EnMAP project for providing funding for this research. We acknowledge support by the Open Access Publication Fund of Freie Universität Berlin. TK would like to thank Dr. Michael Schaale for helpful comments.

Author Contributions: Therese Keck and René Preusker conceived and designed the study. Jürgen Fischer provided the radiative transfer code MOMO. Therese Keck wrote the analysis and simulation programs and analysed the data. All authors discussed and contributed to the results. Therese Keck wrote the manuscript. All authors approved the final manuscript.

Conflicts of Interest: The authors declare no conflict of interest. The founding sponsors had no role in the design of the study; in the collection, analyses, or interpretation of data; in the writing of the manuscript, and in the decision to publish the results.

1. Reinart, A.; Paavel, B.; Pierson, D.; Niklas, S. Inherent and apparent properties of Lake Peipsi, Estonia. Boreal Environment Research 2004, 9, 429-445.

2. Zheng, G.; Stramski, D.; DiGiacomo, P.M. A model for partitioning the light absorption coefficient of natural waters into phytoplankton, nonalgal particulate, and colored dissolved organic components: A case study for the Chesapeake Bay. Journal of Geophysical Research: Oceans 2015, 120, 2601-2621.

3. Morel, A. Bio-optical Models. In Encyclopedia of Ocean Sciences; Elsevier, 2001; pp. 317-326.

4. Bricaud, A.; Morel, A.; Babin, M.; Allali, K.; Claustre, H. Variations of light absorption by suspended particles with chlorophyll a concentration in oceanic (case 1) waters: Analysis and implications for bio-optical models. Journal of Geophysical Research: Oceans 1998, 103, 31033-31044.

5. Loisel, H.; Stramski, D.; Mitchell, B.G.; Fell, F.; Fournier-Sicre, V.; Lemasle, B.; Babin, M. Comparison of the ocean inherent optical properties obtained from measurements and inverse modeling. Applied optics 2001, 40, 2384-97, [arXiv:0148-0227/98/98JC-02712].

6. Doerffer, R.; Schiller, H. The MERIS Case 2 water algorithm. International Journal of Remote Sensing 2007, 28, 517-535.

7. Le, C.; Li, Y.; Zha, Y.; Sun, D. Specific absorption coefficient and the phytoplankton package effect in Lake Taihu, China. Hydrobiologia 2009, 619, 27-37.

8. Nechad, B.; Ruddick, K.; Schroeder, T.; Oubelkheir, K.; Blondeau-Patissier, D.; Cherukuru, N.; Brando, V.; Dekker, A.; Clementson, L.; Banks, A.C.; Maritorena, S.; Werdell, P.J.; Sá, C.; Brotas, V.; Caballero de Frutos, I.; Ahn, Y.H.; Salama, S.; Tilstone, G.; Martinez-Vicente, V.; Foley, D.; McKibben, M.; Nahorniak, J.; Peterson, T.; Siliò-Calzada, A.; Röttgers, R.; Lee, Z.; Peters, M.; Brockmann, C. CoastColour Round Robin data sets: a database to evaluate the performance of algorithms for the retrieval of water quality parameters in coastal waters. Earth System Science Data 2015, 7, 319-348.

9. Valente, A.; Sathyendranath, S.; Brotas, V.; Groom, S.; Grant, M.; Taberner, M.; Antoine, D.; Arnone, R.; Balch, W.M.; Barker, K.; Barlow, R.; Bélanger, S.; Berthon, J.F.; Besiktepe, S.; Brando, V.; Canuti, E.; Chavez, F.; Claustre, H.; Crout, R.; Frouin, R.; García-Soto, C.; Gibb, S.W.; Gould, R.; Hooker, S.; Kahru, M.; Klein, H.; Kratzer, S.; Loisel, H.; McKee, D.; Mitchell, B.G.; Moisan, T.; Muller-Karger, F.; O’Dowd, L.; Ondrusek, M.; Poulton, A.J.; Repecaud, M.; Smyth, T.; Sosik, H.M.; Twardowski, M.; Voss, K.; Werdell, J.; Wernand, M.; Zibordi, G. A compilation of global bio-optical in situ data for ocean-colour satellite applications. Earth System Science Data 2016, 8, 235-252.

10. Gordon, H.R.; Brown, O.B.; Evans, R.H.; Brown, J.W.; Smith, R.C.; Baker, K.S.; Clark, D.K. A semianalytic radiance model of ocean color. Journal of Geophysical Research 1988, 93, 10909.

11. Morel, A. Optical modeling of the upper ocean in relation to its biogenous matter content (case I waters). Journal of Geophysical Research 1988, 93, 10749.

12. O'Reilly, J.E.; Maritorena, S.; Siegel, D.A.; O’Brien, M.C.; Toole, D.; Mitchell, B.G.; Kahru, M.; Chaves, F.P.; Strutton, P.; Cota, G.F.; Hooker, S.B.; McClain, C.R.; Carder, K.L.; Muller-Karger, F.; Harding, L.; 
Magnuson, A.; Phinney, D.; Moore, G.F.; Aiken, J.; Arrigo, K.R.; Letelier, R.; Culver, M. Chapter 2 Ocean Color Chlorophyll a Algorithms for. In SeaWiFS Postlaunch Calibration and Validation Analyses, Part 3; 2000; chapter 2, pp. 8-22.

13. Morel, A.; Prieur, L. Analysis of variations in ocean color1. Limnology and Oceanography 1977, 22, 709-722.

14. Huot, Y.; Brown, C.a.; Cullen, J.J. Retrieval of phytoplankton biomass from simultaneous inversion of reflectance, the diffuse attenuation coefficient, and Sun-induced fluorescence in coastal waters. Journal of Geophysical Research 2007, 112, C06013.

15. Gower, J. On the use of satellite-measured chlorophyll fluorescence for monitoring coastal waters. International Journal of Remote Sensing 2016, 37, 2077-2086.

16. Jerlov, N.G. Influence of Suspended and Dissolved Matter on the Transparency of Sea Water. Tellus 1953, 5, 59-65.

17. Doerffer, R.; Fischer, J. Concentrations of chlorophyll, suspended matter, and gelbstoff in case II waters derived from satellite coastal zone color scanner data with inverse modeling methods. Journal of Geophysical Research 1994, 99, 7457.

18. Odén, S. Die Huminsäuren. Chemische, physikalische und bodenkundliche Forschungen. Kolloidchemische Beihefte 1919, 11, 76-260.

19. Gordon, H.R. Diffuse reflectance of the ocean: the theory of its augmentation by chlorophyll a fluorescence at $685 \mathrm{~nm}$. Applied Optics 1979, 18, 1161.

20. Fischer, J.; Kronfeld, U. Sun-stimulated chlorophyll fluorescence 1: Influence of oceanic properties. International Journal of Remote Sensing 1990, 11, 2125-2147.

21. Schalles, J.F. Optical remote sensing techniques to estimate phytoplankton chlorophyll a concentrations in coastal. In Remote sensing of aquatic coastal ecosystem processes; Richardson, L.L.; LeDrew, E.F., Eds.; Springer Science \& Business Media, 2006; chapter 3, pp. 27-79.

22. Zhou, J.; Gilerson, A.; Ioannou, I.; Hlaing, S.; Schalles, J.; Gross, B.; Moshary, F.; Ahmed, S. Retrieving quantum yield of sun-induced chlorophyll fluorescence near surface from hyperspectral in-situ measurement in productive water. Optics Express 2008, 16, 17468.

23. Pedrós, R.; Moya, I.; Goulas, Y.; Jacquemoud, S. Chlorophyll fluorescence emission spectrum inside a leaf. Photochemical \& Photobiological Sciences 2008, 7, 498.

24. Maxwell, K.; Johnson, G.N. Chlorophyll fluorescence-a practical guide. Journal of Experimental Botany 2000, 51, 659-668.

25. Xing, X.G.; Zhao, D.Z.; Liu, Y.G.; Yang, J.H.; Xiu, P.; Wang, L. An overview of remote sensing of chlorophyll fluorescence. Ocean Science Journal 2007, 42, 49-59.

26. Maritorena, S.; Morel, A.; Gentili, B. Determination of the fluorescence quantum yield by oceanic phytoplankton in their natural habitat. Applied Optics 2000, 39, 6725.

27. Gilerson, A.; Zhou, J.; Hlaing, S.; Ioannou, I.; Schalles, J.; Gross, B.; Moshary, F.; Ahmed, S. Fluorescence component in the reflectance spectra from coastal waters. Dependence on water composition. Optics Express 2007, 15, 15702.

28. Neville, R.a.; Gower, J.F.R. Passive remote sensing of phytoplankton via chlorophyll $\alpha$ fluorescence. Journal of Geophysical Research 1977, 82, 3487-3493.

29. Behrenfeld, M.J.; Westberry, T.K.; Boss, E.S.; O'Malley, R.T.; Siegel, D.A.; Wiggert, J.D.; Franz, B.A.; McClain, C.R.; Feldman, G.C.; Doney, S.C.; Moore, J.K.; Dall'Olmo, G.; Milligan, A.J.; Lima, I.; Mahowald, N. Satellite-detected fluorescence reveals global physiology of ocean phytoplankton. Biogeosciences 2009, 6, 779-794.

30. Hu, C.; Feng, L. Modified MODIS fluorescence line height data product to improve image interpretation for red tide monitoring in the eastern Gulf of Mexico. Journal of Applied Remote Sensing 2016, 11, 012003.

31. Roesler, C.S.; Perry, M.J. In situ phytoplankton absorption, fluorescence emission, and particulate backscattering spectra determined from reflectance. Journal of Geophysical Research 1995, 100, 13279.

32. Claustre, H.; Morel, A.; Babin, M.; Cailliau, C.; Marie, D.; Marty, J.C.; Tailliez, D.; Vaulot, D. Variability in particle attenuation and chlorophyll fluorescence in the tropical Pacific: Scales, patterns, and biogeochemical implications. Journal of Geophysical Research: Oceans 1999, 104, 3401-3422.

33. Zarco-Tejada, P.J; Miller, J.R.; Mohammed, G.H.; Noland, T.L.; Sampson, P.H. Estimation of chlorophyll fluorescence under natural illumination from hyperspectral data. International Journal of Applied Earth Observation and Geoinformation 2001, 3, 321-327. 
34. Letelier, R. An analysis of chlorophyll fluorescence algorithms for the moderate resolution imaging spectrometer (MODIS). Remote Sensing of Environment 1996, 58, 215-223.

35. Gower, J.F.R.; Doerffer, R.; Borstad, G.a. Interpretation of the $685 \mathrm{~nm}$ peak in water-leaving radiance spectra in terms of fluorescence, absorption and scattering, and its observation by MERIS. International Journal of Remote Sensing 1999, 20, 1771-1786.

36. Meroni, M.; Rossini, M.; Guanter, L.; Alonso, L.; Rascher, U.; Colombo, R.; Moreno, J. Remote sensing of solar-induced chlorophyll fluorescence: Review of methods and applications. Remote Sensing of Environment 2009, 113, 2037-2051.

37. Palmer, S.; Odermatt, D.; Hunter, P.; Brockmann, C.; Présing, M.; Balzter, H.; Tóth, V. Satellite remote sensing of phytoplankton phenology in Lake Balaton using 10years of MERIS observations. Remote Sensing of Environment 2015, 158, 441-452.

38. Ahn, Y.H.; Shanmugam, P. Derivation and analysis of the fluorescence algorithms to estimate phytoplankton pigment concentrations in optically complex coastal waters. Journal of Optics A: Pure and Applied Optics 2007, 9, 352-362.

39. Guanter, L.; Kaufmann, H.; Segl, K.; Foerster, S.; Rogass, C.; Chabrillat, S.; Kuester, T.; Hollstein, A.; Rossner, G.; Chlebek, C.; Straif, C.; Fischer, S.; Schrader, S.; Storch, T.; Heiden, U.; Mueller, A.; Bachmann, M.; Mühle, H.; Müller, R.; Habermeyer, M.; Ohndorf, A.; Hill, J.; Buddenbaum, H.; Hostert, P.; van der Linden, S.; Leitão, P.; Rabe, A.; Doerffer, R.; Krasemann, H.; Xi, H.; Mauser, W.; Hank, T.; Locherer, M.; Rast, M.; Staenz, K.; Sang, B. The EnMAP Spaceborne Imaging Spectroscopy Mission for Earth Observation. Remote Sensing 2015, 7, 8830-8857.

40. Doerffer, R.; Schiller, H. Algorithm Theoretical Basis Document ( ATBD ) Lake Water Algorithm for BEAM. Technical Report 1, GKSS, Geesthacht, 2008.

41. Fischer, J.; Grassl, H. Radiative transfer in an atmosphere-ocean system: an azimuthally dependent matrix-operator approach. Applied Optics 1984, 23, 1032.

42. Fell, F.; Fischer, J. Numerical simulation of the light field in the atmosphere-ocean system using the matrix-operator method. Journal of Quantitative Spectroscopy and Radiative Transfer 2001, 69, 351-388.

43. Hollstein, A.; Fischer, J. Radiative transfer solutions for coupled atmosphere ocean systems using the matrix operator technique. Journal of Quantitative Spectroscopy and Radiative Transfer 2012, 113, 536-548.

44. Le, C.; Li, Y.; Zha, Y.; Sun, D.; Huang, C.; Lu, H. A four-band semi-analytical model for estimating chlorophyll a in highly turbid lakes: The case of Taihu Lake, China. Remote Sensing of Environment 2009, $113,1175-1182$.

45. Mitchell, B.G. Algorithms for determining the absorption coefficient for aquatic particulates using the quantitative filter technique. Ocean Optics X. International Society for Optics and Photonics, 1990, Vol. 1302, pp. 137-148, [1011.1669].

46. McClatchey, R.A.; Fenn, R.W.; Selby, J.E.A.; Volz, F.E.; Garing, J.S. Optical Properties of the atmosphere. Technical report, 1972.

47. Lefering, I.; Röttgers, R.; Utschig, C.; McKee, D. Uncertainty budgets for liquid waveguide CDOM absorption measurements. Applied Optics 2017, 56, 6357.

48. Binding, C.; Bowers, D.; Mitchelson-Jacob, E. Estimating suspended sediment concentrations from ocean colour measurements in moderately turbid waters; the impact of variable particle scattering properties. Remote Sensing of Environment 2005, 94, 373-383.

49. Kennedy, J.J. A review of uncertainty in in situ measurements and data sets of sea surface temperature. Reviews of Geophysics 2014, 52, 1-32.

50. Le Menn, M. About uncertainties in practical salinity calculations. Ocean Science 2011, 7, 651-659.

51. Sayer, A.M.; Hsu, N.C.; Bettenhausen, C.; Jeong, M.J. Validation and uncertainty estimates for MODIS Collection 6 "Deep Blue" aerosol data. Journal of Geophysical Research: Atmospheres 2013, 118, 7864-7872.

52. McKee, D.; Piskozub, J.; Röttgers, R.; Reynolds, R.A. Evaluation and Improvement of an Iterative Scattering Correction Scheme for in situ Absorption and Attenuation Measurements. Journal of Atmospheric and Oceanic Technology 2013, 30, 1527-1541. 